\title{
Intersectoral action for health at a municipal level in Cuba
}

\author{
Jerry Spiegel $\cdot$ Milagros Alegret $\cdot$ Veronic Clair $\cdot$ Nino Pagliccia $\cdot$ \\ Barbara Martinez $\cdot$ Mariano Bonet $\cdot$ Annalee Yassi
}

Received: 30 September 2010/Revised: 5 July 2011/Accepted: 18 July 2011/Published online: 16 August 2011

(c) The Author(s) 2011. This article is published with open access at Springerlink.com

\begin{abstract}
Objective To consider how Cuba's acknowledged achievement of excellent health outcomes may relate to how health determinants are addressed intersectorally.

Methods Our team of Canadian and Cuban researchers and health policy practitioners undertook a study to consider the organization and practices involved in addressing health determinants in 2 municipalities ( 1 urban and 1 rural). The study included a questionnaire of municipal Health Council members and others involved in health and non-health sectors, key informant interviews of policy makers, focus groups in each municipality and examination of three common case scenarios.

Results Regular engagement of different sectors and other agencies in addressing health determinants was quite systematic and comparable in both municipalities. Specific policies and organizational structures in support of intersectoral actions were frequently cited and illustrated in case scenarios that demonstrate how maintenance of regular
\end{abstract}

J. Spiegel $(\bowtie) \cdot$ V. Clair · N. Pagliccia · A. Yassi

School of Population and Public Health, Faculty of Medicine,

University of British Columbia, 430-2206 East Mall,

Vancouver, BC V6T 1Z3, Canada

e-mail: Jerry.Spiegel@ubc.ca

M. Alegret · B. Martinez

Centro Provincial de Higiene y Epidemiología,

Santa Clara, Cuba

\section{Bonet}

Instituto Nacional de Higiene, Epidemiología y Microbiología, Havana, Cuba

J. Spiegel

Global Health Research Program, Liu Institute for Global Issues,

Vancouver, BC, Canada linkages facilitates regular pursuit of intersectoral approaches.

Conclusions The study demonstrates the feasibility of examining processes of intersectoral action for health processes and suggests that further examination in evaluating factors such as training, particular practices, etc., can be a fruitful direction to pursue comparatively and with analytical designs.

Keywords Intersectoral - Cuba · Population health . Determinants of health $\cdot$ Health system organization

\section{Introduction}

In reflecting on the legacy of the historic 1978 International Conference on Primary Health Care in Alma Ata, it was observed that "community participation and intersectoral engagement seem to be the weakest strands in primary health care" (Lawn et al. 2008). Recognizing Cuba to be one of the few low or middle income countries to have largely met the ambitious "Health for All by the Year 2000" goals set at Alma Ata, this article examines the role that intersectoral action for health (IAH) has played in this achievement, to consider possible lessons. Our investigation actually grew out of a Canadian - Cuban collaboration begun in the mid-1990s (Spiegel et al. 2006) to study ways of effectively addressing various environmental health challenges (e.g. housing, dengue, drinking water, sanitation)-which drew us to focus on the institutional factors playing a central role in determining success.

As noted by Lawn and colleagues, "national policies can facilitate such collaboration, but only local action can make these synergies happen" (Lawn et al. 2008). We, therefore, set out to investigate the integration of policies 
and practices relevant to intersectoral collaboration at the municipal level, closer to where health impacts are most critically experienced and affected populations are most directly engaged. Our overriding purpose was to better understand how actors conceive of, prioritize and manage health determinants and how intersectorality manifests itself concretely.

\section{Why focus on Cuba?}

Cuba stands out for having achieved excellent health outcomes despite being a poor country (Garrett 2009; Whiteford and Branch 2007), prompting the oft-repeated observation that "[Cubans] live like the poor and die like the rich" (Macintyre and Hadad 2002). Cuba's excellent health indices are all the more impressive as these have been achieved across rural, suburban and urban areas, with limited variation across social gradients (Alegret et al. 2004; Lopez Pardo 2004). That these accomplishments have been made on the "margins of globalization" (Spiegel and Yassi 2004) further suggests the presence of a "natural experiment" for considering systemic influences concerning how IAH can be efficaciously pursued.

Pastor Castell-Florit noted that Cuba's public health policies regarding intersectoral action have evolved in tandem with deepening understanding of population health determinants (Castell-Florit Serrate 2007a, b; Castell-Florit Serrate et al. 2007). As he explains, the Cuban model passed through three stages since the 1959 Revolution. In the first stage, disease-based programming was primarily pursued alongside basic health and non-health (e.g. literacy, sanitation) system strengthening to remedy a situation of profound disparities similar to other Latin American countries. In the second stage, corresponding to the 1970s and 1980s, focus was concentrated on risk, with programming aimed at population groups in relation to healthdisease processes associated with common diseases, and in support of comprehensive health promotion and disease preventive interventions (Castell-Florit Serrate 2007a, b; Pan American Health Organisation 2007). In this context, collaborations were increasingly pursued and decentralization of local capacities initiated, but supports for intersectoral action were not yet systemically in place.

The third stage, signalled by the 1991 Cuban Ministry of Public Health strategic plan: Objectives, Aims, and Guidelines for Improving the Health of the Cuban Population 1992-2000 (Ministry of Public Health Cuba 1991), sharpened the focus on the family and intersectoral collaboration. This plan defined health goals and objectives to be achieved by the year 2000 by reshaping the system despite a profound economic crisis faced in Cuba after the collapse of its Soviet Union trading partner. The strategy involved reorganization and decentralization within government and the National Health System specifically; encouragement of community participation in local decision-making, prioritization and actions consistent with the World Health Organization's "Healthy Cities" movement; creation of health commissions at the national, provincial and municipal levels of government (e.g. Health Council, Committee of Quality of Life and Health); and local task forces (e.g. Prevention Group against HIV/AIDS, Task Force against Use of Illegal Drugs) (Castell-Florit Serrate 2007a, b).

Despite some recognition of high level policies that have supported IAH in Cuba (Public Health Agency of Canada 2008) and attention to the capabilities needed to support its implementation (Castell-Florit Serrate 2007a), there has been very little research published in the peer-review literature regarding how intersectorality actually functions in targeted and everyday circumstances in Cuba. We set out to study the local level intersectoral management of health determinants, to enable others to learn from Cuba's achievements.

\section{Methods}

We applied a mixed methods design, using a two-phased descriptive approach. First, we conducted focus groups and utilized questionnaires to examine the implementation of IAH in municipal spaces by various actors. The questionnaires allowed us to undertaken a quantitative analysis of the extent, nature and diversity of IAH, enhanced by the focus group discussions. Guided by the first phase results, in-depth interviews were then conducted to obtain details on how IAH approaches were put into practice in three common scenarios.

Two municipalities in Cuba's central province of Villa Clara were chosen for the study: Santa Clara, an urban industrial setting, and Camajuaní, a rural agricultural municipality (populations 238,424 and 63,177, respectively, in 2006). These two municipalities were deemed similar to other Cuban municipalities of their sizes (Alegret et al. 2004, 2008). Our purpose in examining two communities was to observe factors that may be attributable to common (provincial or national-level) influences and differences likely attributable to local circumstances.

Research themes were drawn from the literature and aligned with a similar study conducted in Canada (Frankish et al. 2007). Experts from the research team in both Cuba and Canada contributed to adapting the survey and focus group instruments. Two workshops were held with senior scientists and decision-makers of the Cuban health sectors to refine the thinking on the research methodology and enabled a review for face and content validity of all the study instruments (GHRP 2008a, b). 
Participants and participating institutions were identified through intentional sampling based on their known capacity to address health determinants from perspectives from within-local and municipal government, the healthcare sector, as well as non-health sectors and community organizations. The Popular Councils (comprising delegates elected from sub-municipal neighbourhood constituencies) and the polyclinics included in the study were selected by Cuban research team members from those considered typical of each of the two municipalities. With ethical approval granted in Canada and Cuba, focus groups and questionnaires were conducted during the first quarter of 2007. Each focus group lasted $2 \mathrm{~h}$ and was facilitated by a Cuban team member, with a second person responsible for recording the discussion.

Five focus groups were conducted in each of the two municipalities: two comprised participants from four Popular Councils; two comprised healthcare workers from two polyclinics; and one comprised non-health professional members of the Health Council-a structure responsible for health issues at the municipal level, in which healthcare system decision-makers and clinicians participate alongside members of the Municipal People's Power Assembly, the municipal governing body. (The Municipal Assembly is composed of the elected members from all the Popular Councils as well as non-elected representative of Cuban ministries, institutes, sectors and large civil organizations). In Santa Clara, an extra focus group comprised members of the Municipal Unit of Hygiene and Epidemiology which also has responsibilities for health matters. The numbers and composition of focus group participants are shown in Table 1 .

Immediately prior to the focus group discussions, all participants were given a self-administered questionnaire (available on request) including a preamble defining intersectoral collaboration (WHO 1997) as well as the eleven health determinants adapted from previous such questionnaires (Frankish et al. 2007). Participants were asked to identify the organization they represented; to rank in a 5-point Likert scale the importance they attributed to each health determinant listed and their own institution's level of involvement for each determinant; as well as to indicate levels of collaboration with other sectors on each determinant.

All recruited participants responded positively and participated fully. The only exception was the second focus group with Popular Council members in Santa Clara. Due to an unforeseen local event needing the immediate attention of some committee members, only one person from each Popular Council attended this focus group. All focus group participants completed the questionnaire.

The questionnaire descriptive results from the two municipalities were compared using the non-parametric
Table 1 Organizations represented in focus group sessions

\begin{tabular}{|c|c|c|}
\hline & $\begin{array}{l}\text { Santa } \\
\text { Clara }\end{array}$ & Camajuaní \\
\hline \multicolumn{3}{|l|}{ Focus groups } \\
\hline 1-Popular Council 1 and 2 & 12 & 11 \\
\hline 2-Popular Council 3 and 4 & $2^{\mathrm{a}}$ & 8 \\
\hline 3-Municipal Leaders Assembly & 19 & 7 \\
\hline 4-Polyclinic 1 & 16 & 8 \\
\hline 5-Polyclinic 2 & 10 & 9 \\
\hline $\begin{array}{l}\text { 6-Municipal Unit of Hygiene \& } \\
\text { Epidemiology }\end{array}$ & 11 & $\mathrm{n} / \mathrm{a}$ \\
\hline Total number of participants & 70 & 43 \\
\hline \multicolumn{3}{|l|}{ Institutions represented $^{\mathrm{b}}$} \\
\hline Popular Power Council & 17 & 5 \\
\hline Federation of Cuban Women & 2 & 6 \\
\hline Committee in Defense of the Revolution & 2 & 9 \\
\hline Community services $^{c}$ & 1 & 1 \\
\hline Ministry of Justice & 1 & - \\
\hline Ministry of Agriculture & 1 & - \\
\hline Ministry of Economy and Planning & 1 & - \\
\hline National Institute of Hydro Resources ${ }^{\mathrm{d}}$ & 1 & - \\
\hline Ministry of Information \& Communication & 1 & 1 \\
\hline Ministry of Culture & 1 & 1 \\
\hline National Institute of Housing & 1 & - \\
\hline Ministry of Commerce & 1 & 1 \\
\hline Ministry of Education & 1 & 1 \\
\hline Ministry of Basic Industry & 1 & 1 \\
\hline Total Non-Health Sector & 32 & 26 \\
\hline Health Sector & 37 & 17 \\
\hline No answer & 1 & - \\
\hline
\end{tabular}

a This is the focus group that happened at the same time as an unforeseen local event that required the attention of most members of both of those Popular Councils

b Many members of the Popular Council are also members of other institutions such as the Committee in Defense of the Revolution and the Federation of Cuban Women and have identified the organization they represent as such in the questionnaire

c Referred to as Servicios Comunales in Cuba which includes the institutions that collect solid waste, clean the street and provide other such municipal services considered important for health, hygiene and safety

${ }^{\mathrm{d}}$ Responsible for managing water resources including drinking water

Wilcoxon rank-sum test. Further methodological details and analysis conducted using methods of network analysis are described in Pagliccia et al. (2010).

Following preliminary analysis of focus group and questionnaire results, it became clear that no single model of intersectoral action could describe the totality of health actions or programmes. Therefore, Cuban members of the research team conducted two full-day in-depth interviews with policy makers in the Provincial Health Office. Their goal was to document three different yet typical IAH 
Table 2 Percentage responses of long-term full engagement in internal actions on determinants by municipality

\begin{tabular}{lll}
\hline & Santa Clara & Camajuaní \\
\hline Health services & 81.4 & 70.0 \\
Healthy child development & 79.4 & 74.4 \\
Education & 78.1 & 66.7 \\
Gender* & 70.7 & 48.7 \\
Healthy lifestyles & 65.1 & 47.5 \\
Social support \& network* & 59.7 & 34.2 \\
Values and social norms & 58.5 & 42.1 \\
Culture & 58.2 & 41.2 \\
Employment \& work conditions & 50.8 & 46.5 \\
Income \& standard of living & 40.3 & 41.5 \\
Physical environment & 39.3 & 30.8 \\
\hline
\end{tabular}

* Significant difference between communities; non-parametric Wilcoxon rank-sum test $P<.05$

scenarios in the two municipalities. The cases chosen related to: (1) an Aedes Aegypti mosquito infestation (related to dengue), (2) a dysfunctional family and (3) a high-risk pregnancy.

\section{Results}

Level of engagement

Intensity of involvement in health-related activities varied across the sectoral organizations. The percentage of respondents who indicated that their institution had longterm histories for IAH actions for specific determinants is summarized by Table 2 .

Apart from the areas of "Income \& Standard of Living", and "Physical Environment", the majority of Santa Clara institutions were implementing IAH at the highest stage of involvement for all determinants. "Health Services" in Santa Clara (81.4\%) and "Healthy Child Development" in Camajuaní (74.4\%) had the largest percentage of respondents reporting "long term history" of institutional action. The "Physical Environment" determinant obtained the lowest percentage of long-term action in both municipalities (30.8\% for Camajuaní and 39.3\% for Santa Clara). A significant difference in level of involvement between the two municipalities was found only for "Social Support \& Network" and "Gender" (non-parametric Wilcoxon rank-sum test $P<0.05$ ).

Most important actions undertaken

The perceived importance attributed to the various health determinants was similar in each municipality (Fig. 1). In both Santa Clara and Camajuaní, greatest importance was
Mean importance of determinants all organizations

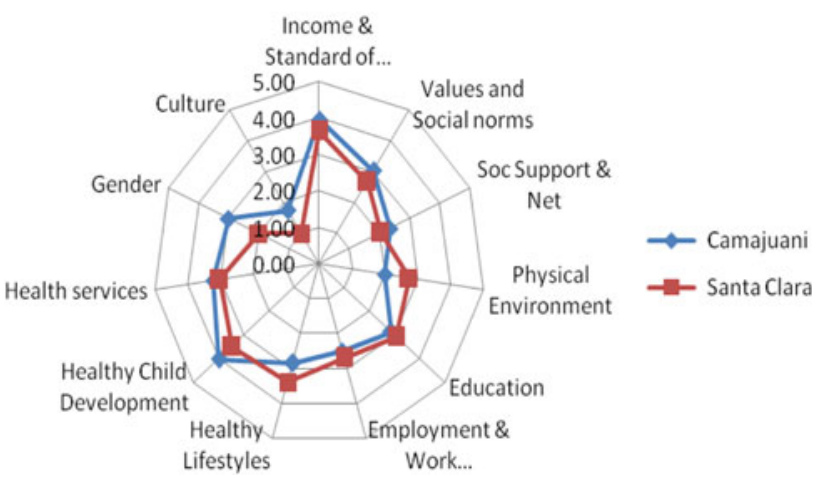

Fig. 1 Mean importance of health determinants by all sectors involved-Santa Clara and Camajuaní

assigned to "Income and Standard of Living" and "Healthy Child Development", with "Culture and Gender" receiving the lowest attention. No significant differences were observed between the two municipalities.

Respondents spoke of a variety of actions being undertaken by their institution for each health determinant. Some such actions are reported later.

Income and Standard of Living: More than 50\% of respondents in Camajuaní mentioned actions to reinforce income levels as a major area of attention. In Santa Clara, the most commonly reported intervention $(>50 \%)$ was "distribution of goods". An illustration of this occurred during the study when a national programme distributing energy efficient refrigerators caused a meeting disruption to accommodate delivery schedules.

\section{Physical environment}

The majority of organizations in both municipalities reported undertaking actions dealing with environmental sanitation, with emphasis in developing campaigns to that effect such as the campaign to "fight vectors" in Camajuaní.

\section{Education}

By and large, organizations in both municipalities focus actions on promotion of "universal education" and creating "opportunities for study".

\section{Employment and working conditions}

The main reported action was around ensuring "guaranteed employment", in addition to "improved working condition" initiatives. Respondents in Santa Clara (19\%) also mentioned "engaging youth in work and study". 


\section{Healthy lifestyles}

The large majority of respondents reported "educational campaigns" for healthy lifestyles. These campaigns address various topics such as nutrition and physical exercise, improved sanitation, decreasing smoking and alcohol consumption, and HIV risk reduction.

\section{Healthy Child Development}

The majority of actions reported here fell under specific programmes such as the Programa de Atención Materno Infantil, coordinated by the Ministry of Public Health. The "Educate Your Child" programme, coordinated by the Ministry of Education, addresses child development from birth to school age. This community-based programme is highly intersectoral, involving the ministries of Public Health, Culture and Sports and various organizations including the Federation of Cuban Women (FMC), the Committee for the Defense of the Revolution (CDR) and the Association of Small Farmers (ANAP).

\section{Gender}

Actions towards equality for women were the most important action category reported $(60 \%$ in Camajuaní and $68 \%$ in Santa Clara). Camajuaní had an additional 30\% of respondents reporting actions towards "incorporating women in the workforce and leadership". For Santa Clara, this percentage was $10 \%$.

\section{Culture}

The largest percentage of respondents reported organizing "book fairs and film festivals" as the most important measures (28 and 38\% in Camajuaní and Santa Clara, respectively) that they pursued.

\section{Level of collaboration}

Table 3 shows that the large majority of respondents in Santa Clara report their institution having a high level of collaboration with other institution(s) on all health determinants. This full collaboration involves "joint planning, execution and evaluation of actions and programs". Whereas 50\% or more respondents in Camajuaní reported full collaboration with another institution only for five determinants, namely Healthy Child Development, Health Services, Education, Healthy Lifestyles and Income and Standard of Living, for other determinants some collaboration was reported-including "formal exchange of information" and "joint planning only". Two determinants, Social Support and Network and Gender, show significant
Table 3 Percentage of respondents reporting high levels of collaboration among sectors on determinants by municipality

\begin{tabular}{lll}
\hline Health determinant & \multicolumn{2}{l}{$\begin{array}{l}\text { Santa Clara } \\
\text { Column percentage }\end{array}$} \\
\hline Healthy child development & 84.9 & 76.5 \\
Income \& standard of living & 80.0 & 63.0 \\
Health services & 77.6 & 68.8 \\
Gender* & 76.2 & 40.9 \\
Education & 75.5 & 65.7 \\
Healthy lifestyles & 73.5 & 63.6 \\
Culture & 69.2 & 46.2 \\
Physical environment & 68.6 & 48.2 \\
Social support and network* & 66.7 & 35.5 \\
Values and social norms & 61.8 & 36.7 \\
Employment \& work conditions & 55.8 & 44.4 \\
\hline
\end{tabular}

Responses to a Likert scale question

* Non-parametric Wilcoxon rank-sum test difference between communities; $P<.05$

Table 4 Crude odds ratios of association between existence of programmes and presence of intersectoral links-Camajuaní and Santa Clara

\begin{tabular}{lll}
\hline Programmes & Camajuaní & Santa Clara \\
\hline Programmes in health services & 0.57 & 3.58 \\
Programmes in healthy child development & 0.65 & 3.50 \\
Programmes in healthy lifestyles & 1.82 & 4.45 \\
\hline
\end{tabular}

differences in the two municipalities (Wilcoxon rank-sum $P<0.05)$ as noted previously.

To better understand the effect of specific programmes on the likelihood of pursuing intersectoral collaborations, three specific areas identified in focus groups were examined in greater depth: Health Services, Healthy Child Development and Healthy Lifestyles. We looked at the likelihood that organizations reporting concrete programmes in these domains also reported having total collaboration with other organizations. The crude odds ratios of operating a programme and maintaining an intersectoral link are presented in Table 4 for the two municipalities.

In Camajuaní, organizations primarily involved in Health Services (0.57) and Healthy Child Development $(0.65)$ were less likely than organizations without such programme to report intersectoral links (odds ratio less than one), while organizations primarily involved in Healthy Lifestyle programmes were more likely to report intersectoral links (odds ratio of 1.82). In contrast, in Santa Clara, organizations with programmes in Health Services are 3.58 times more likely to have intersectoral links than organizations without such programmes. The odds ratios for Healthy Child Development and Healthy Lifestyles are 
Table 5 Percentage of respondents reporting high social cohesion by municipality

\begin{tabular}{lll}
\hline Nature of social cohesion reported & Santa Clara & Camajuaní \\
\hline Between mass organizations and people & 78.1 & 62.5 \\
Among neighbours* & 77.6 & 58.1 \\
Among friends & 77.6 & 88.1 \\
Among women & 76.5 & 83.7 \\
Among family members & 76.1 & 90.5 \\
Among youth & 74.6 & 81.4 \\
Among men & 70.3 & 59.5 \\
Between state organizations and people & 53.1 & 51.2 \\
Between private entrepreneurs and people & 43.3 & 56.1 \\
\hline
\end{tabular}

* Significant association using a Fisher's exact test $(P<0.05)$

3.5 and 4.45 , respectively. For most of the health determinants, close intersectoral collaboration was reported to exist, linking government ministries and agencies, the civil society sector (FMC and CDR) and the health sector (Table 5).

\section{Applying intersectoral approaches}

In-depth interviews with policy makers highlighted that no single model or process is capable of generically describing all instances of intersectoral action and decision-making in Cuba, but that examination of specific examples can best illustrate the flexible ways whereby different sectors interact (Fig. 2).

\section{Scenario 1: Detection of an Aedes Aegypti infestation}

Dengue fever is a growing health concern across Latin America, and several outbreaks have occurred in Cuba since the late 1970s (Bonet et al. 2007). Detection of a breeding site of the dengue vector, the Aedes Aegypti mosquito, was described as a typical starting point for action. Detection occurs through regular inspection of water-containing receptacles and collection of mosquito larvae in houses and open spaces by teams of field workers (campañistas) that had in fact initially been established following a serious dengue outbreak in the early 1980s. The Municipal Office of Hygiene and Epidemiology then tests the samples. If confirmed, the statistics office of the area polyclinic and the area's elected representative (community delegate) are informed. Immediately, intersectoral mechanisms are triggered and the following representatives are convened to the Health Council of the Popular Assembly to meet with health representatives: community delegate, FMC, CDR, Association of Combatants of the Revolution, Communist Party area representative, Water and Sanitation personnel and representatives of workplaces in areas adjacent to the affected area.

The intersectoral team looks at circumstances associated with breeding sites such as garbage deposits, improper water management, abandoned lots and closed or unsanitary households. Based on this, action plans are developed for all sectors, to be implemented within 3 days. Common actions involve the FMC and CDR conducting community mobilization to clean areas and improve citizen participation in detecting risks, as well as health professionals fumigating infested sites and identifying dengue cases. Other actions may include health education and promotion. The detection of a case of dengue in a family medical centre or polyclinic also triggers the search for breeding sites that could lead to further transmission as well as isolation of virus-affected patients.

\section{Scenario 2: A dysfunctional family}

A dysfunctional family, for example one in which the father may be alcoholic, the mother unemployed or a child truant, can be identified by the social worker, polyclinic staff or schoolteacher. This type of situation is the responsibility of the Prevention Group in the health area. This intersectoral space comprises the community delegate, the social worker, a health and education representative and a municipal representative from both the Ministry of the Interior and the Ministry of Labour \& Social Security. The Prevention Group collectively assesses the situation, determines the possible solutions and assigns tasks for implementation involving the whole family to avoid marginalization. In such a case, a typical IAH action taken is the registration of the father in a detoxification programme supervised by health personnel, a social worker and the appropriate linked civil society (mass) organizations. The Ministry of Labour \& Social Security representative would help the mother to reintegrate into the work force by linking her to available jobs. The Ministry of Education representative might be able to help her obtain additional training. The Ministry of Health representative would provide psychological support to facilitate the reintegration. Finally, health and education personnel together with mass organizations would help the child to be reintegrated in the school system.

\section{Scenario 3: Mother-child health}

The death of an infant is considered a very serious, albeit rare, event, and therefore, the occurrence of a child death prompts a full intersectoral review. The Health Council of the Popular Assembly monitors these issues during pregnancy. Possible causes such as low birth weight from insufficient nutrition of the pregnant mother is investigated. 

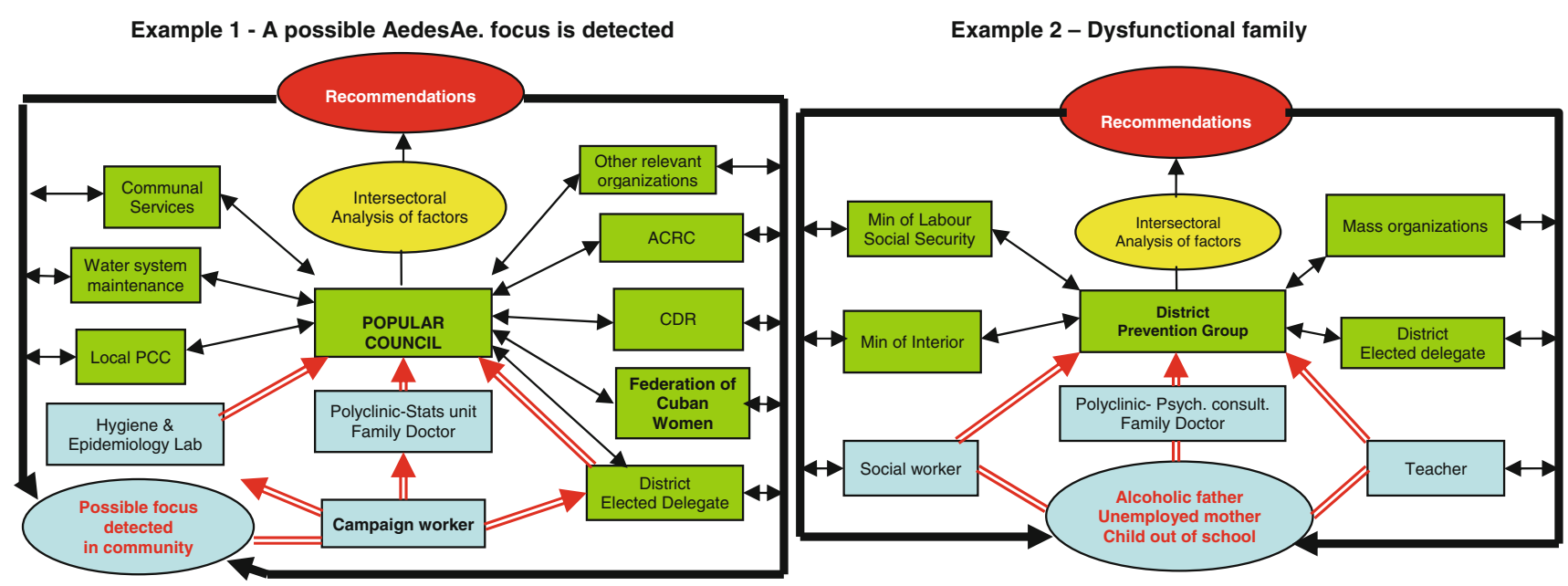

Example 3 - High Risk pregnancy

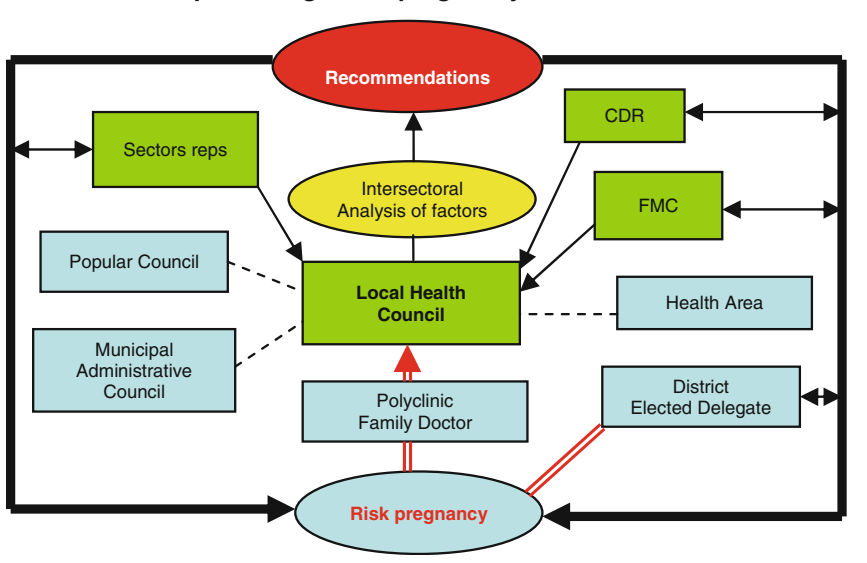

Glossary

ACRC: Association of Combatants of the Cuban Revolution

CDR: Committee for the Defense of the Revolution

FMC: Cuban Federation of Women

Popular Council: Local government

PCC: Cuban Communist Party

Elected delegate: To the Popular Council

Polyclinic: Neighbourhood multi-service health centre

Family doctor: In each neighbourhood

Legend

$\longleftrightarrow$ Links between unit to other sectors

Direct organizational linkages

$\Longrightarrow$ Response / Link triggered by "scenario" event

$\longrightarrow$ Intersectoral action channeled to address issues

Fig. 2 Scenarios used to illustrate the ways whereby different sectors interact with each other

To avoid such adverse events, health professionals and the FMC identify pregnant women at risk and then assign them to a special home (hogar materno) in the community to ensure proper medical follow by family practitioners. Nutrition and provision of adequate diet are the responsibility of other specialists as well as the agriculture sector.

While the precise character of IAH interaction is thus distinct in each scenario, what can be observed in all three circumstances is the presence of a coordinating function facilitated by the municipal Health Council and/or affiliated Prevention Units in local health areas.

\section{Discussion}

As part of the work carried out for the World Health Organization's Commission on Social Determinants of Health (CSDH), a preliminary systematic review of approaches to undertaking intersectoral action in 18 countries (Public Health Agency of Canada 2007, 2008) was conducted. In synthesizing these case studies, it was observed that "IAH is a complex, political process, involving diverse groups in wide-ranging sets of activities. Consequently, how IAH interventions are developed and implemented matters as much as what is done" (Health Systems Knowledge Network 2007, p. 15).

As IAH can be seen as "a process through which actors belonging to different sectors unite to address a given health-related issue", "coalition theory" has been proposed as a useful conceptual framework (O’Neill et al. 1997) to explain this dynamic. In addition to parameters typically highlighted as influencing the pursuit of collaborative actions (rewards people expect to gain, assets they have to bring, non-utilitarian preference they develop, rules for decision-making), attention has been drawn to the importance of "organizational context". Our study of Cuba's distinct characteristics has provided an excellent opportunity to explore this consideration.

The presence in Cuba of primary health service personnel and public health expertise provided through neighbourhood-based polyclinics reinforces a place-based "connectedness" with a capacity to collect and act on 
relevant information. In addition to formal structures with an explicit health mandate, there is an established scaffolding to support a broader "intersectoral space" whereby those with a potential role to play in addressing health determinants are linked in a standing body, the Health Council, which is accountable for producing positive results. Furthermore, the inclusion of representatives from community organizations provides a space for including broader public involvement as well as raising areas of concern. An examination of "Civil society and the health system in Cuba" conducted for the CSDH provides a more thorough documentation of how such social participation is systematically pursued (Ochoa and Visbal 2007).

While Healthy Child Development was observed in Cuba to be the area receiving the greatest attention for intersectoral action, as it was in the Canadian context (Frankish et al. 2007), we found that the extent of IAH implementation was at a considerably higher degree of intensity in Cuba. Furthermore, IAH attention more frequently extended to areas such as employment and working conditions, which were observed to receive far less attention in Canadian jurisdictions. As in high income countries, an outstanding IAH challenge is perhaps illustrated by the relatively low levels of IAH collaboration in the domain of built environments where intensified proactive pursuit of strategies is needed to deal with chronic disease and ageing, which are also prominent health concerns in Cuba.

The results presented here are in concordance with the network analysis that was conducted of these same two Cuban municipal Health Councils, demonstrating high levels of intersectoral health-related actions as well as striking similarities in the two municipalities (Pagliccia et al. 2010). These results suggest that the repeated presence of functioning intersectoral networks is supported by an organizational structure and policy orientation to support such activity as illustrated by the cases presented. In this regard, interest has been expressed in Cuba for a strengthening of evaluation and training capabilities for carrying out IAH activities (Castell-Florit Serrate 2010).

Our study suggests that the Cuban experience validates the Alma Ata and Ottawa Charter propositions that "organizational and community participation" are integral parts of producing good health results, something that has been explicitly observed by Kath (2010) and Spiegel (2009). That the head of the municipal Health Council is by statute a vice-president of the People's Power Councils (Castell-Florit Serrate et al. 2007), the most basic level of elected government in Cuba, underscores the value placed on health by the political leadership in Cuba.

From an international perspective, despite the Ottawa Charter's highlighting of the strategic importance of IAH in 1986, it has been repeatedly observed that dominant economic and political conditions and priorities in the decades following the Ottawa Charter restricted the realization of this vision. In particular, the era of globalization that ensued generated a "harsher economic climate" that favoured policy coherence around fiscal austerity rather that the systematic pursuit of health and health equity in most countries (Sindall 1997). For municipal governments subject to neoliberal pressures, emphasis on "New Public Management Theory" (Hambleton 2004; Pierre and Rothstein 2008) created pressures for cost-cutting and the pursuit of "efficiencies", with concepts of community empowerment, decentralization and integration primarily subordinated to being adaptive strategies to compensate for weakened public sector commitments rather than as supported mechanisms for promoting health (Lapsley 2009). In contrast, the structural reforms and policy measures adopted in Cuba in 1991 to support IAH amid a severe economic crisis responded to a very different expression of "political will".

The attention given to IAH by the Commission on Social Determinants of Health and associated studies clearly speaks of increased importance to not only understanding factors that can affect health, but to better grasp organizational ways in which this can be achieved—so that our capacity for conducting effective interventions is strengthened (Galobardes 2010; Potvin 2009). As observed by O'Neill et al. (1997), it is vital that we go beyond essentially ideological health promotion affirmations of the value of intersectoral approaches. We must indeed generate knowledge about a science of "how" these practices can be effectively applied. Examining what is done in Cuba is certainly helpful in this regard.

Acknowledgments This study was supported by funding from the Canadian Institutes of Health Research. We would like to thank all Cuban participants in the focus groups for donating their valuable time to this study and all Cuban and Canadian members of the research team whose ideas have contributed to this rewarding interaction.

Open Access This article is distributed under the terms of the Creative Commons Attribution Noncommercial License which permits any noncommercial use, distribution, and reproduction in any medium, provided the original author(s) and source are credited.

\section{References}

Alegret M, Spiegel JM, Yassi A (2004) Importance of stratification and territorial ordering in prospection. Prediction and surveillance in public health. Presented at 4th annual meeting of the Canadian Coalition for Global Health Research, CCGHR, Ottawa

Alegret M, Grau R, Rodríguez M (2008) La clasificación multivariante de áreas geográficas como una alternativa útil a la investigación salubrista [Multivariate classification of geographic areas as a useful alternative for public health research]. Rev Cub Salud Pública 34 
Bonet M, Spiegel J, Ibarra A, Kouri G, Pintre A, Yassi A (2007) An integrated ecosystem approach for sustainable prevention and control of dengue in Central Havana. Int J Occup Environ Health 13:188-194

Castell-Florit Serrate P (2007a) Comprensión conceptual y factores que intervienen en el desarrollo de la intersectorialidad. Rev Cub Salud Pública 33

Castell-Florit Serrate P (2007b) La obra de Abelardo Ramírez Márquez: paradigma de la salud pública cubana. Rev Cub Salud Pública 33

Castell-Florit Serrate P (2010) Intersectoral health strategies: from discourse to action. MEDICC Rev 12:48

Castell-Florit Serrate, Carnota O, Mirabal M, Santana C, Hadda J, Cabrera T (2007) Study on intersector practices in health in Cuba. Document complementing the report to the Pan American Health Organization

Frankish CJ, Moulton GE, Quantz D, Carson AJ, Casebeer AL, Eyles JD et al (2007) Addressing the non-medical determinants of health. Can J Pub Health 98:41-47

Galobardes B (2010) Closing the gap in a generation: what more research do we need? Int J Public Health 55:453-455

Garrett L (2009) All for universal health coverage. Lancet 374:1294-1299

Global Health Research Program (2008a) Intersectoral action to improve health: applying evidence, achieving impact. Workshop proceedings, Vancouver, BC, 2008. http://www.ghrp.ubc.ca/files/ 2011/08/Vancouver-Intersectorality-workshop-Proceedings_NOV2008.pdf

Global Health Research Program (2008b) Intersectorality in the social production of health: sharing perspectives and experiences to orient a Cuba-Canada research program. Workshop proceedings, Havana, Cuba, 2008. http://www.ghrp.ubc.ca/files/2011/08/HavanaIntersectorality-proceedings_Feb-2008.pdf

Hambleton R (2004) Beyond new public management: city leadership, democratic renewal, and the politics of place. Paper presented at the City Futures International Conference, Chicago. http://www. uic.edu/cuppa/cityfutures/papers/webpapers/cityfuturespapers/ session8_1/8_1beyondnew.pdf. Accessed 30 June 2011

Health Systems Knowledge Network (2007) Challenging inequity through health systems-final report of the Health Systems Knowledge Network

Kath E (2010) Social relations and the Cuban health miracle. Transaction Press, New Brunswick

Lapsley I (2009) New public management: the Cruellist invention of the human spirit? Abacus 45:1-21

Lawn JE, Rohde J, Rifkin S, Were M, Paul VK, Chopra M (2008) Alma-Ata 30 years on: revolutionary, relevant, and time to revitalise. Lancet 372:917-927

Lopez Pardo CM (2004) El desarrollo humano y la equidad en cuba: Una visión actualizada. Rev Cub Salud Pública 30: Available from: http://scielo.sld.cu/scielo.php?script=sci_arttext\&pid=S0864$34662004000100006 \& \operatorname{lng}=\mathrm{es} \& n r m=$ iso

Macintyre KCE, Hadad J (2002) Cuba. In: Fried BJ, Gaydos LM (eds) World health systems: challenges and perspectives. Health Administration Press, Chicago
Ministry of Public Health Cuba (1991) Objectives, aims, and guidelines for improving the health of the Cuban population 1992-2000

O’Neill M, Lemieux V, Groleau G, Fortin J, Lamarche P (1997) Coalition theory as a framework for understanding and implementing intersectoral health-related interventions. Health Promot Int 12:79-87

Ochoa FR, Visbal LA (2007) Civil society and health system in Cuba. Case study commissioned by the Health Systems Knowledge Network of the WHO Commission on the Social Determinants of Health

Pagliccia N, Spiegel J, Alegret M, Bonet M, Martinez A, Yassi A (2010) Network analysis as a tool to assess the intersectoral management of health determinants at the local level: a report from an exploratory study of two Cuban municipalities. Soc Sci Med 71:394-399

Pan American Health Organisation (2007) Study on intersector practices in health in Cuba. In: Castell-Florit Serrate P, Lauzán OC, Jean-Claude MM, Espinosa CS, Hadda JH, González TC (eds) Report to the Pan American Health Organization, Washington, pp 11

Pierre J, Rothstein B (2008) How should the state behave? The New Public Management versus the New Weberianism. Paper presented at the conference "New Public Management and the Quality of Government." Gothenburg, November 13-14, 2008 http://www.qog.pol.gu.se/working_papers/SOG\% 20papers/Pierre\%20\&\%20Rothstein\%20-\%20SOG\%20Conference $\% 20$ Nov08.pdf (accessed June 30, 2011)

Potvin L (2009) Yes! More research is needed; but not just any research. Int J Public Health 54:127-128

Public Health Agency of Canada (2007) Crossing sectors. PHAC, Ottawa

Public Health Agency of Canada (2008) Health equity through intersectoral action: an analysis of 18 country case studies. In: Public Health Agency of Canada Ministry of Health (ed)

Sindall C (1997) Intersectoral collaboration: the best of times, the worst of times. Health Promot Int 12:5-7

Spiegel J (2009) Beyond health services: channeling capacity to manage health determinants. In: Mason S, Strug D, Beder J (eds) Community health care in Cuba. Lyceum Press, Chicago, pp 108-129

Spiegel JM, Yassi A (2004) Lessons from the margins of globalization: appreciating the Cuban health paradox. J Public Health Pol 25:96-121

Spiegel J, Garcia M, Bonet M, Yassi A (2006) Learning together: a Canada-Cuba research collaboration to improve the sustainable management of environmental health risks. Can J Public Health 97:50-55

Whiteford L, Branch L (2007) Primary health care in Cuba: the other revolution. Rowman \& Littlefield, Lanham

World Health Organization (WHO) (1997) Intersectoral action for health: A cornerstone for health-for-all in the twenty-first century. Report on an international conference held in Halifax, 20-23 April 1997 